\title{
Assessing the Effectiveness of Innovative Pedagogy and Lecture Method on Students Academic Achievement and Retention in Computer Programming
}

\author{
Christian Basil Omeh (iD) and Chijioke Jonathan Olelewe \\ Department of Computer and Robotics Education, University of Nigeria, Nsukka, Nigeria \\ Correspondence should be addressed to Christian Basil Omeh; christian.omeh@unn.edu.ng
}

Received 7 October 2021; Revised 12 November 2021; Accepted 15 November 2021; Published 24 December 2021

Academic Editor: Ehsan Namaziandost

Copyright (c) 2021 Christian Basil Omeh and Chijioke Jonathan Olelewe. This is an open access article distributed under the Creative Commons Attribution License, which permits unrestricted use, distribution, and reproduction in any medium, provided the original work is properly cited.

\begin{abstract}
Education prepares one for the world of work; hence, the adoption of the innovative instructional approach employed in the process of teaching and learning is key to the attainment of this goal. To mitigate students' poor achievement in computer programming $(\mathrm{CP})$, innovative pedagogy (IP) was adopted to make students become active learners in classroom learning. In this study, a quasiexperimental design was used and nonrandomized the subject with pretest and posttest. Students $(N=145)$ were nonrandomized to the treatment and control groups. The researchers conducted a repeated measure of analysis of variance to determine the change between the experimental and control groups. Students' attributes were tested for differences by comparing categorical data with chisquare statistics. The interaction effect was determined using an analysis of covariance. The results revealed that the experimental group's $\mathrm{CP}$ achievement test results outperformed those of the control group at posttest and retention tests. Furthermore, the findings of the study show that there is no significant difference in students' academic achievement across ability levels and gender. Also, there is no interaction between the pretest and the IP. The study, therefore, recommends that computer educators should adopt innovative teaching practices in their day-to-day teaching since it is more creative, learner-centered, and improved student engagement.
\end{abstract}

\section{Introduction}

Programming is the art of designing executable codes to solve a particular task [1]. It involves analyzing tasks, designing algorithms to solve a task, among others. The art of converting an algorithm into a computer program is called computer programming. Computer programming $(\mathrm{CP})$ is an introductory course offered by undergraduate students to enable them to acquire relevant skills for work [2-4]. It is, therefore, essential to acquire basic skills and knowledge of $\mathrm{CP}$ such as writing and testing code, data visualization skills, automating machine skills, and program development skills [5-7] to match with fast-changing trends in education and the world of work [8]. Additionally, the educational content of CP is constantly evolving in terms of scope as a result of recent studies conducted in the field of computer programming, such as evolving from assembling language to object-orientated programming such as $\mathrm{C}, \mathrm{C}++$, and Python [9]. Recently, effective and efficient ways of learning concepts such as the Internet of things IOTs [10], cloud computing, and machine learning [11] are current trends in the fields of CP. This contemporary trend is seen to have a significant impact on CP's learning content [12].

Notwithstanding the importance of $\mathrm{CP}$ in providing skilled personnel and a trained workforce that will be employable in industry or for self-reliance [13, 14], the achievement of students has continued to decline over time. This poor performance has become a source of worry to stakeholders in the educational sector and employers of labor [15-18]. Available records from the University of Nigeria Nsukka in Enugu state have shown that the student's achievement in computer programming courses is on the marginal. For instance, available records have shown that between the 2014 and 2018 academic sessions 370 candidates 
that sat for CP exams had the following grade represented: $20 \%$ scored above 60 marks while $80 \%$ scored less than 50 marks. This poor academic achievement in programming is attributed to several factors such as teaching methods employed $[19,20]$, learning style employed by the students $[21,22]$, and large class size [1]. In Nigeria, most lecturers are still using traditional talk and chalk which does not effectively facilitate learning [23-28].

Research has shown that teaching methods influence students' academic achievement [29-32]. The author stresses that the traditional method/lecture method (LM) focuses more on the standardized test without giving students room to think out a solution to a problem; thus, students are constrained to rote learning [33]. According to [34], problem-solving skills are not encouraged in the traditional method of teaching because it lacks flexibility and cannot meet today's educational needs of learners and society with regard to hands-on training or skill acquisition [35-37].

Today, efforts are made by educational stakeholders to bring about curriculum reform that advocates for a learnercentered approach to teaching in schools [38, 39]. These reforms focus on the introduction and adoption of modern innovative pedagogy, which helps students' skill development and application of critical thinking in problem-solving when it comes to CP [40]; self-directed learning [41] and working collaboratively are essential [42]. IP tends to mean improving the existing teaching and learning methods in a creative but value increasing way $[43,44]$. IP is the inclusion of modern teaching techniques to enhance teaching and learning $[45,46]$. As IP is about doing things in a new or different way, it is critical to use appropriate methods that guarantee improved learning outcomes [47].

Literature has identified IP for enhancing teaching and learning including virtual reality, task-based learning, crossover learning, learning through argumentation, flipped learning, context-based learning (CBL), peer-facilitated tutoring, and problem-based learning (PBL) [48, 49]. For instance, $\mathrm{CBL}$ is a flexible modern method that quickly integrated technology into the learning process. It is a method of teaching that allows a learner to explore their environment in teaching and learning. That is making use of real-life examples to explain the concept under study. Many scholars have defined CBL in different ways. According to $[50,51], \mathrm{CBL}$ refers to learning theoretical concepts and involves using invented and real-life examples in the teaching environment to understand the practical experience and actual subject matter. CBL is a learning strategy driven by the real-world context, culture, and tools in the learning environment [52]. CBL is a learner-centered approach and applies skills to solve an identified problem [53]. CBL has successfully been implemented in education [54], medicine [55] and technology education [56], and chemistry [57] and is seen to improve learning outcomes as much as a problem-based learning approach.

Similarly, PBL is another IP that empowers the learner to combine theory and practices and skills to develop solutions and apply knowledge $[58,59]$. PBL provides an environment in which students can draw upon prior knowledge. It presents the learner with an ill-structured, open-ended, real- world problem, and students work in a small group to solve learning needs and develop a solution for the identified problem. Problem-based learning has been employed in many disciplines, for example, business education [60], medical education [61], social work education [62], health education [63], and engineering education [64]. In engineering education, it has proved to aid retention, motivate students, and improve achievement. Additionally, research has demonstrated that problem-based learning enhances students' problem-solving abilities [65], reasoning skills and analytical [66], interpersonal skills [67], self-directed learning skills [68], attitudes toward the course or subject [69], academic achievement, and long-term knowledge retention [70, 71]. PBL has gained traction in the field of computer science and engineering, such as algorithms [72], digital design [73], and communication systems [74]. It also improves student retention [75], motivation, decision making [76], and deeper learning [77]. Owing to the strength of CBL and PBL approaches, its adoption as active learning in teaching and learning of CP is likely to help address students' achievement and retention in the learning of the computer programming course. It is therefore hoped that utilization of an IP (CBL and PBL) approach in teaching and learning $\mathrm{CP}$ can help improve students' higher-order thinking, communication, problem-solving, and information retrieval which are required to become an efficient programmer. Additionally, it strengthens information acquisition and practical skills necessary for achievement and resolves real-world situations in CP.

The student's active participation in IP sessions has been influenced by many factors such as gender, socioeconomic background, educational resources, background knowledge level of students, age, and ability level [78-80]. The ability level of an individual is the observed level of performance in achieving a particular task. This ability differs from person to person as a result of the cognitive or health development of an individual $[81,82]$. Studies have shown that student ability level affects the students in the learning process $[83,84]$. Some studies have also shown that instructional strategies employed by the teacher influence the achievement of low-ability students [85, 86]. However, [87, 88] argue that higher-ability students achieve better than lowability ones. This study, therefore, sought to assess the effectiveness of IP interaction on students' academic achievement and retention in computer programming.

\subsection{Hypotheses}

Hypothesis 1: there is a significant difference in the mean achievement scores of students taught CP using IP and those taught using LM

Hypothesis 2: there is a significant difference in the mean achievement scores of male and female students taught computer programming using IP

Hypothesis 3: there is a statistically significant difference in the mean achievement scores of CP students exposed to IP in the low-ability, medium-ability, and high-ability groups 
Hypothesis 4: there is a statistically significant interaction effect between gender and the mean achievement scores of students taught $\mathrm{CP}$ using IP

\section{Method}

2.1. Ethical Consideration. Ethical approval was taken from the Postgraduate Board of Department of Computer and Robotics Education University of Nigeria Nsukka as a Master's Postgraduate research for the first author while the second author is the supervisor. A consent form was obtained from the department.

2.2. Design. The design of this study was nonrandomized control groups. According to [89], a quasi-experimental design is one in which intact classes or preexisting groups serve as the experimental and control groups rather than random sampling and group assignment. The intact group was utilized in this study to avoid interfering with normal school schedules and activities at the universities that participate in the study. However, the intact classes were randomly assigned to the experimental and control groups through a toss of a coin. Any intact class that scores a head was assigned to the experimental group (IP) and any class that scores a tail was assigned to a control group (LM) as shown in Table 1.

2.3. Participants. The study participants consisted of $145 \mathrm{CP}$ year two students in public universities in Enugu state, Nigeria, which met the inclusion criteria for the research. STATA software was used to find the sample size [90] depending on the magnitude of the effect of power $(1-B=0.8)$, alpha $(a=0.05)$, and effect size of $F=0.26$, as shown in Figure 1. The researcher obtained written permission from the departments of computer science education at Enugu State University of Science and Technology (ESUT) and the Computer and Robotics Education Department at the University of Nigeria Nsukka (UNN) before the conduct of the study. Table 2 presents the demographic data of the students.

The study enrolled a total of 145 students. The experimental group consisted of $34(40 \%)$ male students and 51 (60\%) female students, whereas the control group consisted of $23(38.8 \%)$ male students and 37 (61.6\%) female students. From the analysis of the Chi-square table, it can be observed that there is no significant difference between gender and the ability of the students. Out of those in the experimental group, 37 (43.5\%) had low ability (aptitude), 22 (25.8\%) had the medium ability (aptitude), and 26 (30.5\%) had a higher ability (aptitude), and in the control group, 40 (66.6\%) had low ability (aptitude), 20 (33.3\%) had a medium ability (aptitude), and 25 (41.7\%) had the higher ability (aptitude).

2.4. Procedure. The researcher visited the public universities accredited by the national university commission (NUC) in the study area. The University of Nigeria Nsukka was used based on the required facilities: second-year students with
TABLE 1: The randomized pretest and posttest control group design.

\begin{tabular}{lccccc}
\hline Group & $\begin{array}{c}\text { Non- } \\
\text { R }\end{array}$ & Pretest & Treatment & Posttest & Retention \\
\hline $\begin{array}{l}\text { Experimental } \\
\text { (E) }\end{array}$ & NR & O1 & X & O2 & O3 \\
Control (C) & NR & O1 & - & O2 & O3 \\
\hline
\end{tabular}

NR: nonrandom assignment of 145 second-year students; O1: pretest administered for experimental and control groups, respectively; O2: posttest administered for the control and experimental groups, respectively; O3: retention test administered for the experimental and control groups; $\mathrm{X}$ : treatment for innovative pedagogy; —: no treatment.

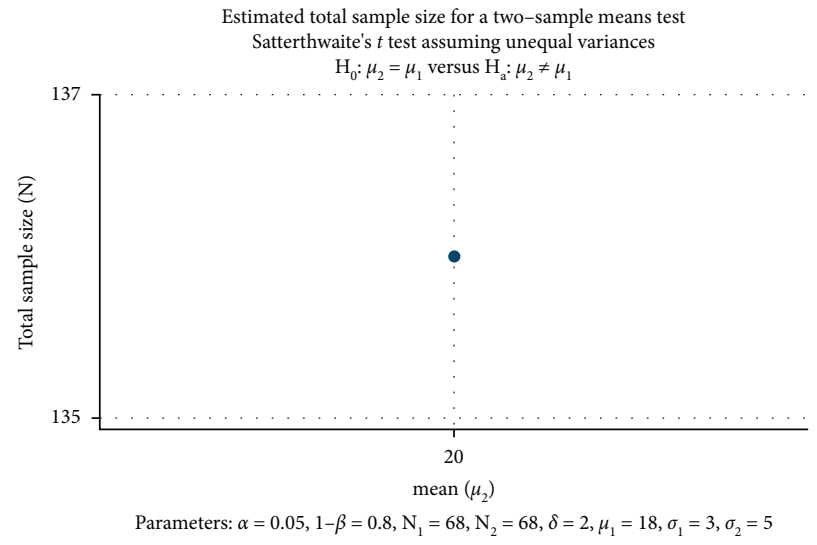

Figure 1: Sample size determination. The study participants consisted of $145 \mathrm{CP}$ year two students in public universities in Enugu state, Nigeria, which met the inclusion criteria for the research. STATA software was used to find the sample size [90] depending on the magnitude of the effect of power $(1-B=0.8)$, alpha $(a=0.05)$, and effect size of $F=0.26$.

TABle 2: Demographic data of students demonstrating the equality of baselines.

\begin{tabular}{lcccc}
\hline Characteristics & $\begin{array}{c}\text { IP group } n \\
(\%)\end{array}$ & $\begin{array}{c}\text { Control group } n \\
(\%)\end{array}$ & $X^{2}$ & Sig \\
\hline Gender & & & & \\
$\quad$ Male & $34(40 \%)$ & $23(38.8 \%)$ & 0.474 & NS \\
$\quad$ Female & $51(60 \%)$ & $37(61.6 \%)$ & & \\
$\begin{array}{l}\text { Previous } \\
\text { experience }\end{array}$ & & & & \\
$\quad$ Low ability & $37(43.6 \%)$ & $40(47.1 \%)$ & & \\
$\quad \begin{array}{l}\text { Medium ability } \\
\quad \text { High ability }\end{array}$ & $22(25.9 \%)$ & $20(23.5 \%)$ & 0.74 & NS \\
\hline
\end{tabular}

IP: innovative pedagogy; NS: not significant; $X^{2}$ : Chi-square.

two streams of lecturers with five years and above working experience, with a class size of 85 students. The research assistant screened the students by using some criteria for the selection of students for the study. Such criteria include the following. Students should have $75 \%$ attendance rate stipulated by the university for a student to be qualified to write any examination and must have passed the course CP (COS 201). Also, students possess study materials and a manual for the course and a functional computer system (laptop). The students must have registered for the course in the university portal, and a consent form should be signed by the student. 
A simple nonrandomization technique was used where the study's intact classes were divided into experimental and control groups at random through a toss of a coin labeled EG (experimental group) or CG (control group). 60 students were in the control group while 85 students were in the treatment group. The student's ability group was determined using student's achievement scores obtained from introduction to CP (COS201) in their first-semester course examination of the two universities.

Based on the ability group, the experimental group has $n=85$ students (low ability, $n=37$; medium ability, $n=22$; and higher ability, $n=26$ ) and the control group (low ability, $n=40$; medium ability, $n=20$; and higher ability, $n=25)$. An attendant policy of a minimum of $75 \%$ by the university council was strictly adhered to; in other words, to control for attrition, attending lab sessions and solving questions in the lab manual, including continuous assessment, were mandatory for students. The research assistants also doubled as lecturers and technologists to ensure students' active participation. The researcher organized a five-day workshop for technologists and lecturers on the training of IP packages developed for the study. Hence, each training session lasted about an hour before the commencement of the experiment.

The initial knowledge of students' academic achievement was determined using a pretest for both groups. After the pretest, an intervention was conducted on the treatment group and not included in the control group. The researcher developed an IP package after taking into account the Maastricht seven-jump model [91], the developmental procedure for the PBL model [92], the developmental procedure of CBL [93], and Olelewe developmental procedure on IP [21]. The intervention package consists of an IP lesson plan and IP instruction manual developed by the researcher after review from a selected expert in the field of $\mathrm{CP}$. The package serves as a guide for the lecturer, technologist, and the students during the teaching and learning process such as instructional objectives, strategy, problem situations, instructional materials, students and teacher activities, assessment, instructional procedures for the students, experimental procedure, and group task activities. The IP package was developed by the researcher (Appendix C).

The treatment for the two groups lasted for ten weeks of $2 \mathrm{hrs}$ per session ( $2 \mathrm{hrs}$ twice each for lecturer and lab sessions every week). With a post-posttest that was administered five weeks after the posttest, there were three tests at three different times: pretest (CPAT), posttest (CPAT2), and post-posttest (CPRT). Pretest was reshuffled and readministered as posttest and post-posttest for the two groups. The researcher used the blinding technique to conceal the assignment sequence to control for selection and expectation bias. This also helped to avoid lecturers and students manipulating and predicting the sequence of assignments.

Also, to control for newness to experiment such as control of novelty effect, the researcher keeps learning environmental condition, duration in teaching, topics covered, facilities used, the language of instruction, and teaching time and scope covered that were the same for both classes [94-96]. Furthermore, before the experiment, there was an interaction between the students and teacher on IP procedure two weeks before the start. This was to enlighten the students and divide the students into five different groups-each with a name tag and identification name as suggested by the students. The name tag was presented in the first session, followed by the problem the students want to solve. The students started from known to unknown; each group discussion led to the knowledge building and development of a hypothesis to solve the identified problem. Each session that ends, students can independently study to learn more about the problem discussed. Students surfed the Internet and visited the library for more information about the identified problem. In the next discussion session, the students shared information from a personal study based on the problem identified through presentation and peer discussion to the group. Each group leader presents the solution to the group session of what they learned in the individual group. The ending part of the session is used for the group leader to harmonize and share their group experience, discovery, or findings with other groups' members.

With regard to the control group, the LM followed a standard procedure using the lesson plan prepared by the researchers. It covers the same subject matter and content area as the experimental group. The students were allowed to use different textbooks and study material in the cause of the study. Throughout the intervention time, the control group students used LM as the same lesson duration as the experimental group.

2.5. Measures. The Computer Programming Assessment Test (CPAT) comprises 35 multiple-choice questions based on the computer programming $(\mathrm{CP})$ course material as shown in Appendix B. The study used the CPAT as a pretest, posttest, and posttest instrument. Blooms Taxonomy of the cognitive domain [97] following the table of specifications was used (see Appendix A). CPAT of about 60 questions items were adopted (https://www. tutorialspoint.com 2019) to find the adequacy in line with the current sample to determine the psychometric test analysis of CPAT (see Appendix B). The distraction index, discriminant computed index, and difficulty index from the student's scores were used. Out of 60 questions, 25 were discarded while 35 were used. The 35 items have a distraction index of $0.50-0.80$, a discriminant index of 0.05 , and the difficulty index of $0.40-0.50$. There were 70 points for the 35 questions, 2 points for the correct response, and 0 points for the inappropriate response. Three experts who are senior lecturers with over 10 years of teaching experience were used to establish the content validity while Kuder-Richardson K-R 20 was used to establish the reliability of the instrument which yielded an index of 0.87 . To establish the instrument's dependability, a test-retest procedure was utilized on a representative sample of $40 \mathrm{CP}$ students from Nnamdi Azikwe University in Awka within two weeks. Reliability ability estimate $[98,99]$ is considered because all the items' scale does not have difficulty levels that influenced the choice of using K-K20. 
2.6. Data Analysis. SPSS (version 23) was used to analyze the data, and the significance threshold for all tests was set at 0.05. An analysis of covariance (ANCOVA) was deemed adequate for determining the difference between the treatment's initial effects on the dependent variable. Again, because the study involved pretest and posttesting, intact classes, the statistical technique used to analyze the hypothesis allowed the researcher to correct for the initial group difference. ANCOVA was used to compare the means of the two groups. Simultaneously, the Chi-square test was used to find out whether the demographic data of the participants (students) were comparable in terms of their characteristics.

\section{Results}

Conducted analysis of variance (ANOVA) to determine whether there is a significant difference in the mean achievement scores on the computer programming achievement exam (CPAT) between students exposed to IP and those exposed to LM. Table 3 summarizes the results for students in the experimental and control groups throughout three evaluation periods. There was no baseline difference in CPAT scores between the two groups at the time of the pretest $(F[2.145]=3.516, P=0.175)$ (see Table 3$)$. Postintervention outcome revealed a significant increase from pretest to posttest $(F[2.145]=65.77 P<0.001)$ for the experimental group, whereas the control group showed no significant difference over the same duration. The postposttest also showed a significant increase in CPRT score (see Table 3).

The hypothesis that there is a significant difference in CPAT achievement scores between male and female students taught using IP was tested using ANOVA. Table 4 shows that there is no significant difference in student achievement scores by gender $(F[1.84]=-0.705, P=0.412)$, with mean scores and standard deviation for male (72.21 and 12.25) and female (64.54 and 10.54) students, respectively, in the experimental group using the CPAT.

According to the hypothesis, there is no significant difference in CPAT achievement scores between students with low-, medium-, and higher-ability levels exposed to IP. As shown in Table 5, there was a considerable disparity in students' achievement scores according to their ability level $(F[1.84]=78.432, P<0.001)$; the pretest result ranges between low $(16.84 \pm 1.22)$, medium $(23.45 \pm 0.88)$, and higher $(36 \pm 1.62)$ students using CPAT (see Table 5). However, in the posttest and retention scores, there was no substantial difference in achievement scores, according to the results. At posttest score, $F[1.84]=4.201, P=0.132$, with the following ability levels: low $(46.24 \pm 4.42)$ medium $(48.40 \pm 3.22)$, and higher ability $(49.64 \pm 4.22)$. At retention score, $F[1.84]=4.032, P=0.101$, with the following ability levels: low $(45.54 \pm 1.54)$, medium $(48.94 \pm 2.40)$, and higher ability $(50.04 \pm 5.53)$.

Furthermore, to determine if treatment and gender ratings had a substantial interaction impact on CP students taught using IP and those taught with LM with regard to gender, ANCOVA was conducted as shown in
Table 6. As the significant level corresponding to the group* gender is 0.935 which is greater than the 0.05 level of significance, no interaction effect of pretest and innovative pedagogy was observed. Also, Figure 2 shows a graphical mean achievement score of LM (control groups) and IP (experimental group); the parallel line shows no interaction effect. This means that the experimental group achievement was not affected by the pretest. Therefore, experimental group achievement scores performed significantly better than the control group.

\section{Discussion}

The results revealed that students taught using innovative pedagogy (CBL and $\mathrm{PBL}$ ) had higher achievement means scores in computer programming than those taught using LM (see Table 3). This finding is in line with [100] stating that the use of innovative teaching improved academic achievement in Mathematics. Also, there is a significant difference as shown in Tables 5 and 6 between the mean academic score of students taught computer programming using innovative pedagogy and those taught using lecture methods. The result shows that gender differences did not significantly affect students' academic performance scores in computer programming when students were exposed to IP. These results are in line with the study of [101], which shows that female and male students reached the same par and will continue to enhance student achievement. From the current and previous studies, one can deduce that female and male students can collaborate and compete favorably in a given course of study $[102,103]$. Table 6 also indicates that there is no interaction effect, therefore confirming that there is a difference between the treatment and control groups. These findings support the view of [54] that the traditional method of teaching has been improved with newer pedagogical approaches. Furthermore, the findings of this research work indicate that there is a notable disparity in the academic achievement of students who employed innovative teaching methods, as opposed to the LM [104-106]. Thus, these findings are consistent with those of [107], who found that using innovative teaching methods aids students with low, average, and higher ability levels in math, meaning that there were significant differences in IP on student performance at all three levels of ability. Reference [108] also found that using IP enhanced student performance and helped in reducing diversity among students. Hence, as shown in Table 5, there was a considerable disparity in students' achievement scores according to their ability level.

Perhaps, the findings of this study can be attributed to students being actively engaged in the learning activities associated with computer programming. According to [109], the use of active learning strategies helped students in achieving mastery of higher-level programming skills through critical thinking, problem-solving, and collaborative learning. Thus, with IP integration, teachers were able to maintain concentration and deep learning among the students which is why the treatment group outperformed the control group in computer 
TABLE 3: ANOVA summary statistic on computer programming student's academic achievement.

\begin{tabular}{|c|c|c|c|c|c|}
\hline Test & Treatment group $(n=85) M \pm \mathrm{SD}$ & Control group $(n=60) M \pm \mathrm{SD}$ & $\mathrm{DF}$ & $F$ & Sig. \\
\hline Pretest & $25.27 \pm 11.76$ & $22.24 \pm 7.03$ & $(2.145)$ & 3.516 & 0.175 \\
\hline Posttest & $66.41 \pm 11.402$ & $55.28 \pm 8.69$ & $(2.145)$ & 65.80 & 0.001 \\
\hline Retention & $73.20 \pm 8.71$ & $57.66 \pm 6.74$ & $(2.145)$ & 131.885 & 0.001 \\
\hline
\end{tabular}

$M=$ mean; $\mathrm{DF}=$ degree of freedom; $F=f$-ratio; $\mathrm{SD}=$ standard deviation.

TABLE 4: Summary of ANOVA statistic of treatment group with respect to gender.

\begin{tabular}{lccccc}
\hline Test & Male $(n=34) M \pm \mathrm{SD}$ & Female $(n=51) M \pm \mathrm{SD}$ & $\mathrm{d} f$ & $F$ & Sig \\
\hline CPAT & $72.21 \pm 12.25$ & $64.54 \pm 10.54$ & $(1.84)$ & 0.705 & 0.412 \\
\hline
\end{tabular}

$M=$ mean; $\mathrm{SD}=$ standard deviation; $\mathrm{CPAT}=$ computer programming achievement test; $F=f$-ratio; $\mathrm{d} f=$ degree of freedom.

TABLE 5: Summary of ANOVA statistics of the experimental group with respect to ability levels.

\begin{tabular}{|c|c|c|c|c|c|c|}
\hline Test & LA $(n=37) M \pm \mathrm{SD}$ & MA $(n=22)$ & $\mathrm{HA}(n=26) M \pm \mathrm{SD}$ & $\mathrm{d} f$ & $F$ & Sig. \\
\hline Pretest & $16.84 \pm 1.22$ & $23.45 \pm 0.88$ & $36 \pm 1.62$ & $(1.84)$ & 78.435 & $<0.01$ \\
\hline Posttest & $46.24 \pm 4.42$ & $48.40 \pm 3.22$ & $49.64 \pm 4.22$ & $(1.84)$ & 4.201 & 0.132 \\
\hline Retention & $45.54 \pm 1.54$ & $48.94 \pm 2.40$ & $50.04 \pm 5.53$ & $(1.84)$ & 4.032 & 0.101 \\
\hline
\end{tabular}

$M=$ mean; LA = low ability; $\mathrm{MA}=$ medium ability; $\mathrm{HA}=$ the higher ability; $F=f$-ratio; $\mathrm{d} f=$ of freedom; $\mathrm{SD}=$ standard deviation.

TABLE 6: Test of an interaction effect between the impact of the subjects (ANCOVA) for computer programming.

\begin{tabular}{lcccccc}
\hline Source & Type III sum of squares & $\mathrm{d} f$ & Mean square & $F$ & Sig. & Partial eta squared \\
\hline Corrected model & $3280.515^{\mathrm{a}}$ & 4 & 820.129 & 8.676 & 0.000 & 0.348 \\
Intercept & 23303.669 & 1 & 23303.669 & 246.512 & 0.000 & 0.791 \\
Pretest & 71.259 & 1 & 71.259 & 0.754 & 0.388 & 0.011 \\
Group & 1508.307 & 1 & 1508.307 & 15.955 & 0.000 & 0.197 \\
Gender & 1089.488 & 1 & 1089.488 & 11.525 & 0.001 & 0.151 \\
Group* Gender & .640 & 1 & 0.640 & 0.007 & 0.935 & \\
Error & 6144.685 & 65 & 94.534 & & & \\
Total & 276772.000 & 70 & & & & \\
Corrected total & 9425.200 & 69 & & & & \\
\hline
\end{tabular}

${ }^{\mathrm{a}} R$ squared $=0.348$ (adjusted $R$ squared $=0.308$ ).

programming. Also, the structured content, students' curiosity, and eagerness to learn as well as active participation in the teaching and learning process $[33,34,36]$ are indicators of better performance. Based on this, current studies have established that a combination of traditional teaching methods with active teaching techniques like context-based learning, problem-based learning, among others is an effective means of achieving innovative teaching and learning of practical skills and theory [110]. This implies that the adoption of IP in teaching and learning of $\mathrm{CP}$ helped to promote active participation, encourage monitoring of learnings progress, and also aid the students to work collaboratively and promote research among university students. Implication for the study is that implementation of innovative pedagogy in the teaching and learning computer programming will help to provide an enabling environment for students to engage in active learning that is characterized by learner-centeredness rather than a teachercentered approach and thus be able to explore collaboration and teamwork as well as improvisation for facility inadequacies in universities in Enugu state. Furthermore, another implication is that innovative pedagogy exposes learner through real-life experience and provide a working environment, work habits, competencies, and skills required for the world of work.
4.1. Suggestion for Further Studies. The following is suggested for further research. A study should be conducted to investigate the challenges and capacity-building needs of universities for the effective application of modern instructional techniques such as big data and others for the quality teaching of students. Also, a study should be carried out to determine the effect of context-based learning and problem-based learning on students' achievement and interest in computer hardware maintenance courses in tertiary institutions in Nigeria. Finally, this study should be replicated in other geopolitical zones of the country such as south-south, northwest, and northeast.

4.2. Limitations of the Study. Despite the positive outcome of this study in favor of innovative pedagogy utilization, one of its weaknesses is the study's small sample size; hence, one may wonder about the efficacy of the research in terms of generalization of the research findings. Low statistical power from a small sample size, according to [111], is that the sample size is not bad for generalization. Accordingly, a small sample size reduces the likelihood of identifying an actual effect. The sample size, however, has no bearing on the 


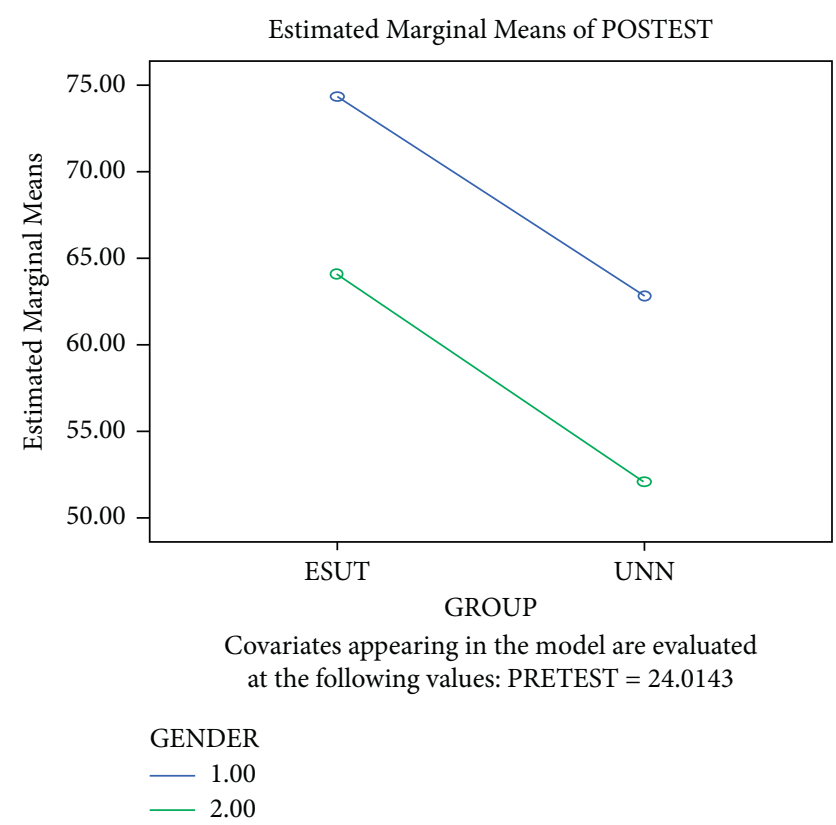

Figure 2: Plot of pretest and treatment conditions. It shows a graphical mean achievement score of LM (control groups) and IP (experimental group); the parallel line shows no interaction effect. This means that the experimental group achievement was not affected by the pretest. Therefore, experimental group achievement scores performed significantly better than the control group.

current investigation because, according to [112], if the power of a statistical test is between 0.80 and 1 , the result would be affected. See Table 2; the sample size did not affect the study; therefore, the sample size is suitable for this study. Another limitation is the quasi-experimental research design where randomization is not feasible because of intact class. Hence, the imbalance between sample sizes may be a source of bias to the result. This study equally recommends that future research should aim at determining the efficacy of IP by considering a larger population.

\section{Conclusion}

The study added to the body of knowledge by demonstrating the efficacy of IP and LM on academic achievement and retention of students in $\mathrm{CP}$. Based on the findings of this study, the study concludes that the use of innovative pedagogy greatly enhanced undergraduate students' academic achievement and retention in computer programming. Hence, the need for IP in teaching and learning CP in universities is warranted since $\mathrm{CP}$ has to do with the handson training, real-world application of knowledge and skills necessary for employment, and a self-reliant and independent individual that can effectively and efficiently program and build simple applications. Thus, computer science lectures are encouraged to employ innovative pedagogical approaches that can be effectively combined to achieve active learning across learning experiences particularly in computer science subjects at the university level of education in Nigeria.

\section{Data Availability}

The data used to support the findings of this study are available upon request to the corresponding author (christian.omeh@unn.edu.ng).

\section{Conflicts of Interest}

The authors declared no potential conflicts of interest concerning the research, authorship, and/or publication of this article.

\section{Acknowledgments}

The authors wish to thank the students who participated in the study especially the treatment group for their commitment.

\section{Supplementary Materials}

Appendix A: the study used the CPAT as a pretest, posttest, and posttest instrument. Blooms taxonomy of the cognitive domain following the table of specifications. CPAT of about 60 questions items was adopted (https://www.tutorialspoint.com 2019). Appendix B: the Computer Programming Assessment Test (CPAT) comprises 35 multiple-choice questions based on the computer programming $(\mathrm{CP})$ course material. Appendix C: a training guide for computer programming on how to use the innovative pedagogy (IP) technique in the classroom. (Supplementary Materials)

\section{References}

[1] S. Ho, S. Chean, I. Chai, and C. H. Tan, "Engineering meaningful computing education: programming learning experience model," in Proceedings of the 2019 IEEE International Conference on Industrial Engineering and Engineering Management (IEEM), pp. 925-929, IEEE, Macao, China, December 2019.

[2] M. S. Gunbatar, "Examination of undergraduate and associate degree students' computer programming attitude and self-efficacy according to thinking style, gender and experience," Contemporary Educational Technology, vol. 9, no. 4, pp. 354-373, 2018.

[3] D. Jegede, "Challenges facing the administration of ICT infrastructural facilities in public primary schools in Nigeria," Electronic Research Journal of Engineering, Computer and Applied Sciences, vol. 1, pp. 30-40, 2019.

[4] Federal Republic of Nigeria (FRN), National Policy on Education, Nigeria Education Research and Development Council (NERDC), Lagos, Nigeria, 6th edition, 2013.

[5] M.-J. Tsai, C.-Y. Wang, and P.-F. Hsu, "Developing the computer programming self-efficacy scale for computer literacy education," Journal of Educational Computing Research, vol. 56, no. 8, pp. 1345-1360, 2019.

[6] M. B. Maina, Y. G. Mohammed, A. M. Bukar et al., "African neuroscience on the global stage: Nigeria as a model," European Journal of Neuroscience, vol. 49, no. 12, pp. 15441551, 2019.

[7] T. I. Chia and O. I. Oyeniran, "Determining the anatomy of anatomy educators," Journal of Taibah University Medical Sciences, vol. 15, no. 2, pp. 102-109, 2020. 
[8] S. Cassidy and P. Eachus, "Developing the computer user self-efficacy (cuse) scale: investigating the relationship between computer self-efficacy, gender and experience with computers," Journal of Educational Computing Research, vol. 26, no. 2, pp. 133-153, 2002.

[9] J. Nouri, L. Zhang, L. Mannila, and E. Norén, “Development of computational thinking, digital competence and 21st century skills when learning programming in K-9," $E d u$ cation Inquiry, vol. 11, no. 1, pp. 1-17, 2020.

[10] S. Sridharan and R. Balakrishnan, Foundations of Discrete Mathematics with Algorithms and Programming, Chapman and Hall/CRC, Boca Raton, FL, USA, 2018.

[11] T. Alodwan and M. Almosa, "The effect of a computer program based on analysis, design, development, implementation and evaluation (ADDIE) in improving ninth graders' listening and reading comprehension skills in English in Jordan," English Language Teaching, vol. 11, no. 4, pp. 43-51, 2018.

[12] A. Fluck, M. Webb, M. Cox et al., "Arguing for computer science in the school curriculum," Journal of educational Technology \& Society, vol. 19, no. 3, pp. 38-46, 2016.

[13] M. Kassab, J. DeFranco, and P. Laplante, "A systematic literature review on Internet of things in education: benefits and challenges," Journal of Computer Assisted Learning, vol. 36, no. 2, pp. 115-127, 2020.

[14] I. Goodfellow, Y. Bengio, and A. Courville, Deep Learning (Adaptive Computation and Machine Learning Series), MIT Press, Cambridge, MA, USA, 2016.

[15] C. Odo and A. Odo, "Effect of simulation on students' interest in programming language in secondary schools in Enugu education zone of Nigeria," International Journal of Information and Education Technology, vol. 6, p. 477, 2016.

[16] J. Chetty and D. van der Westhuizen, "Toward a pedagogy centering on computer programming for learners in South Africa: an educational design research approach," in Proceedings of the EdMedia+ Innovate Learning, pp. 732-740, Association for the Advancement of Computing in Education (AACE), Tampere, Finland, June 2014.

[17] F. Benmarrakchi, J. El Kafi, and A. Elhore, "Communication technology for users with specific learning disabilities," Procedia Computer Science, vol. 110, pp. 258-265, 2017.

[18] S. Proskura and S. Lytvynova, "Organization of independent studying of future bachelors in computer science within higher education institutions of Ukraine," in Proceedings of the 14th International Conference on ICT in Education, Research and Industrial Applications, Integration, Harmonization and Knowledge Transfer, pp. 348-358, Kyiv, Ukraine, May 2018.

[19] J. Msane, B. Mutanga, and T. Chani, “Students' perception of the effect of cognitive factors in determining success in computer programming: a case study," International Journal of Advanced Computer Science and Applications, vol. 11, no. $7,2020$.

[20] J. Okekeokosisi and E. Okigbo, Computer Programming in the South-South, Nigerian Federal Universities, AJSTME, vol. 4, no. 1, pp. 72-83, 2018.

[21] A. Zhang, C. Olelewe, C. Orji et al., "Effects of innovative and traditional teaching methods on technical college students' achievement in computer craft practices," SAGE Open, vol. 10, Article ID 2158244020982986, 2020.

[22] K. Resch and I. Schrittesser, "Using the service-learning approach to bridge the gap between theory and practice in teacher education," International Journal of Inclusive Education, pp. 1-15, 2021.
[23] E. Ifinedo and M. Kankaanranta, "Understanding the influence of context in technology integration from teacher educators' perspective," Technology, Pedagogy and Education, vol. 30, no. 2, pp. 201-215, 2021.

[24] R. O. Azor, U. D. Asogwa, E. N. Ogwu, and A. A. Apeh, "YouTube audio-visual documentaries: effect on Nigeria students' achievement and interest in history curriculum," The Journal of Educational Research, vol. 113, no. 5, pp. 317-326, 2020.

[25] H. A. Bada, T. F. Tengku Ariffin, and H. B. Nordin, "The effectiveness of teachers in Nigerian secondary schools: the role of instructional leadership of principals," International Journal of Leadership in Education, pp. 1-28, 2020.

[26] P. A. Igwe, D. Lock, and D. G. Rugara, "What factors determine the development of employability skills in Nigerian higher education?" Innovations in Education and Teaching International, pp. 1-12, 2020.

[27] B. O. Obuka and F. O. Ukwueze, "Challenges and strategies for sustainable clinical legal education in Nigeria," The Law Teacher, vol. 54, no. 3, pp. 385-399, 2020.

[28] U. C. Okolie, E. N. Ogwu, C. U. Osuji, F. N. Ogba, P. A. Igwe, and S. O. Obih, "A critical perspective on TVET teachers' pedagogical practices: insights into the guiding pedagogical principles in practice," Journal of Vocational Education \& Training, pp. 1-20, 2021.

[29] Y. Yousaf, M. Shoaib, M. A. Hassan, and U. Habiba, "An intelligent content provider based on students learning style to increase their engagement level and performance," Interactive Learning Environments, pp. 1-14, 2021.

[30] C. Troussas, F. Giannakas, C. Sgouropoulou, and I. Voyiatzis, "Collaborative activities recommendation based on students' collaborative learning styles using ANN and WSM," Interactive Learning Environments, pp. 1-14, 2020.

[31] K. Bertills, M. Granlund, Ö. Dahlström, and L. Augustine, "Relationships between physical education (PE) teaching and student self-efficacy, aptitude to participate in PE and functional skills: with a special focus on students with disabilities," Physical Education and Sport Pedagogy, vol. 23, no. 4, pp. 387-401, 2018.

[32] N. I. Edeh, E. O. Ugwoke, and E. O. Anaele, "Effects of innovative pedagogies on academic achievement and development of 21 st-century skills of taxation students in colleges of education," Innovations in Education and Teaching International, pp. 1-10, 2021.

[33] E. Eze, "Why secondary school geography students perform poorly in external examinations," Journal of Geography, vol. 120, no. 2, pp. 51-60, 2021.

[34] C. Biamba, O. Chidimma, O. Chinwe, M. Kelechi, and N. Chinyere, "Assessing democratic classroom practices among secondary school civic education teachers in the global south: case study of south east Nigeria," Cogent Education, vol. 8, Article ID 1896425, 2021.

[35] F. E. Okonofua, L. F. C. Ntoimo, B. F. Ekezue et al., "Outcomes of a multifaceted intervention to improve maternal satisfaction with care in secondary hospitals in Nigeria," Global Health Action, vol. 13, no. 1, Article ID 1856470, 2020.

[36] C. T. Orji and T. C. Ogbuanya, "Mediating roles of ability beliefs and intrinsic motivation in PBL and engagement in practical skills relations among electrical/electronic education undergraduate," Innovations in Education and Teaching International, pp. 1-11, 2020. 
[37] S. Wurdinger and P. Allison, "Faculty perceptions and use of experiential learning in higher education," Journal of E-Learning and Knowledge Society, vol. 13, no. 1, 2017.

[38] Y.-D. Li, G.-H. Ding, and C.-Y. Zhang, "Effects of learnercentred education on academic achievement: a meta-analysis," Educational Studies, pp. 1-14, 2021.

[39] N. Sakata, M. Candappa, and M. Oketch, "Pupils' experiences with learner-centred pedagogy in Tanzania," Compare: A Journal of Comparative and International Education, pp. 1-19, 2021.

[40] A. Adamu, A. U. Tsiga, and S. S. Zuilkowski, "Teaching reading in northern Nigeria: the challenges of large class size," Pedagogy, Culture \& Society, pp. 1-18, 2020.

[41] D. Aduba and O. Mayowa-Adebara, "Online platforms used for teaching and learning during the COVID-19 era: the case of LIS students in Delta State University, Abraka," International Information \& Library Review, pp. 1-36, 2020.

[42] U. Okolie, P. Igwe, I. Mong, H. Nwosu, C. Kanu, and C. Ojemuyide, "Enhancing students' critical thinking skills through engagement with innovative pedagogical practices in global south," Higher Education Research \& Development, pp. 1-15, 2021.

[43] H. Lee and C. Mori, "Reflective practices and self-directed learning competencies in second language university classes," Asia Pacific Journal of Education, vol. 41, pp. 130-151, 2021.

[44] O. Chidi Nuel-Jean and M. Okoye, "Relevance of libraries and librarians in distance education programs of universities in Nigeria," Journal of Library \& Information Services in Distance Learning, vol. 14, pp. 141-159, 2020.

[45] S. Olimov, "The innovation process is a priority in the development of pedagogical sciences," European Journal of Research Development and Sustainability, vol. 2, 2021.

[46] G. Mukhamedov, U. Khodjamkulov, and A. Shofkorov, "Pedagogical education cluster: content and form," Theoretical \& Applied Science, vol. 81, pp. 250-257, 2020.

[47] D. Khoshimova, D. Otajonova, and G. Khaldarchayeva, "Modern technologies in teaching foreign languages," Academic Research in Educational Sciences, vol. 3, 2020.

[48] T. Lupión-Cobos, R. López-Castilla, and Á. Blanco-López, "What do science teachers think about developing scientific competences through context-based teaching? A case study," International Journal of Science Education, vol. 39, pp. 937-963, 2017.

[49] E. Rached and M. Grangeat, "French teachers' informal formative assessment in the context of inquiry-based learning," International Journal of Science Education, vol. 43, pp. 385-406, 2021.

[50] S. Sutaphan and C. Yuenyong, "STEM education teaching approach: inquiry from the context based," Journal of Physics: Conference Series, vol. 1340, no. 1, Article ID 012003, 2019.

[51] V. Uskov, J. Bakken, A. Penumatsa, C. Heinemann, and R. Rachakonda, "Smart pedagogy for smart universities," in Proceedings of the International Conference on Smart Education and Smart E-Learning, pp. 3-16, Springer, Vilamoura, Portugal, June 2017.

[52] R. Yarmatov and M. Ahmedova, "Innovative approach to teaching English on the basis of studying advanced foreign experience in the preparation of future teachers," JSPI Scientific Publications Archive, vol. 1, pp. 1-7, 2020.

[53] W. J. Jacob and V. Gokbel, "Global higher education learning outcomes and financial trends: comparative and innovative approaches," International Journal of Educational Development, vol. 58, pp. 5-17, 2018.

[54] C. Olelewe, F. Doherty, C. Orji, and I. Aneyo, "Effects of innovative pedagogy integration in electrical installation and maintenance works in Enugu and Lagos states technical colleges," The International Journal of Electrical Engineering \& Education, Article ID 0020720921997051, 2021.

[55] M. Sharples, R. Herodotou, C. Koh, and L. Wong, Innovating Pedagogy 2016: Open University Innovation Report 5, Institute of Educational Technology, The Open University, Milton Keynes, UK, 2016.

[56] J. Worrell and J. Profetto-McGrath, "Critical thinking as an outcome of context-based learning among post RN students: a literature review," Nurse Education Today, vol. 27, pp. 420-426, 2007.

[57] V. Darkwah, C. Ross, B. Williams, and H. Madill, "Undergraduate nursing student self-efficacy in patient education in a context-based learning program," Journal of Nursing Education, vol. 50, pp. 579-582, 2011.

[58] K. Yu, S. Fan, and K. Lin, "Enhancing students'problemsolving skills through context-based learning," International Journal of Science and Mathematics Education, vol. 13, pp. 1377-1401, 2015.

[59] S. Avargil, O. Herscovitz, and Y. Dori, "Teaching thinking skills in context-based learning: teachers' challenges and assessment knowledge," Journal of Science Education and Technology, vol. 21, pp. 207-225, 2012.

[60] L. Mann, R. Chang, S. Chandrasekaran et al., "From problem-based learning to practice-based education: a framework for shaping future engineers," European Journal of Engineering Education, vol. 46, pp. 27-47, 2021.

[61] M. Gustin, M. Abbiati, R. Bonvin, M. Gerbase, and A. Baroffio, "Integrated problem-based learning versus lectures: a path analysis modelling of the relationships between educational context and learning approaches," Medical Education Online, vol. 23, Article ID 1489690, 2018.

[62] Y. Delaney, B. Pattinson, J. McCarthy, and S. Beecham, "Transitioning from traditional to problem-based learning in management education: the case of a frontline manager skills development programme," Innovations in Education and Teaching International, vol. 54, pp. 214-222, 2017.

[63] H. Lin and G. Hwang, "Research trends of flipped classroom studies for medical courses: a review of journal publications from 2008 to 2017 based on the technology-enhanced learning model," Interactive Learning Environments, vol. 27, pp. 1011-1027, 2019.

[64] M. Vinjamuri, B. Warde, and P. Kolb, "The reflective diary: an experiential tool for enhancing social work students' research learning," Social Work Education, vol. 36, pp. 933-945, 2017.

[65] J. Martyn, R. Terwijn, M. Kek, and H. Huijser, "Exploring the relationships between teaching, approaches to learning and critical thinking in a problem-based learning foundation nursing course," Nurse Education Today, vol. 34, pp. 829835, 2014.

[66] M. Ebner and A. Holzinger, "Successful implementation of user-centered game based learning in higher education: an example from civil engineering," Computers \& Education, vol. 49, pp. 873-890, 2007.

[67] F. Dochy, M. Segers, P. Van den Bossche, and D. Gijbels, "Effects of problem-based learning: a meta-analysis," Learning and Instruction, vol. 13, pp. 533-568, 2003.

[68] A. Shishigu, A. Hailu, and Z. Anibo, "Problem-based learning and conceptual understanding of college female 
students in physics," Eurasia Journal of Mathematics, Science and Technology Education, vol. 14, pp. 145-154, 2017.

[69] M. Espey, "Enhancing critical thinking using team-based learning," Higher Education Research \& Development, vol. 37, pp. 15-29, 2018.

[70] S. Şendağ and H. Odabaşı, "Effects of an online problembased learning course on content knowledge acquisition and critical thinking skills," Computers \& Education, vol. 53, pp. 132-141, 2009.

[71] M. Sullivan, M. Hitchcock, and G. Dunnington, "Peer and self assessment during problem-based tutorials," The American Journal of Surgery, vol. 177, pp. 266-269, 1999.

[72] V. Irawan and E. Sutadji, "Blended learning based on schoology: effort of improvement learning outcome and practicum chance in vocational high school," Cogent Education, vol. 4, Article ID 1282031, 2017.

[73] I. Garcia, R. James, P. Bischof, and A. Baroffio, "Self-observation and peer feedback as a faculty development approach for problem-based learning tutors: a program evaluation," Teaching and Learning in Medicine, vol. 29, pp. 313-325, 2017.

[74] J. Beringer, "Application of problem based learning through research investigation," Journal of Geography in Higher Education, vol. 31, pp. 445-457, 2007.

[75] M. Kek and H. Huijser, "The power of problem-based learning in developing critical thinking skills: preparing students for tomorrow's digital futures in today's classrooms," Higher Education Research \& Development, vol. 30, pp. 329-341, 2011.

[76] L. Xu, J. Zhao, C. Li, C. Li, X. Wang, and Z. Xie, "Simulation and prediction of hydrological processes based on firefly algorithm with deep learning and support vector for regression," International Journal of Parallel, Emergent and Distributed Systems, vol. 35, pp. 288-296, 2020.

[77] D. Parmelee, L. Michaelsen, S. Cook, and P. Hudes, "Teambased learning: a practical guide: AMEE guide no. 65," Medical Teacher, vol. 34, pp. e275-e287, 2012.

[78] C. Robert, Machine Learning, a Probabilistic Perspective, MIT Press, Cambridge, MA, USA, 2014.

[79] L. Brodie, "eProblem-based learning: problem-based learning using virtual teams," European Journal of Engineering Education, vol. 34, pp. 497-509, 2009.

[80] O. Akinola and K. Nosiru, "Factors influencing students' performance in computer programming: a fuzzy set operations approach," International Journal of Advances in Engineering \& Technology, vol. 7, p. 1141, 2014.

[81] F. Kazemi, M. Yektayar, and A. Abad, "Investigation the impact of chess play on developing meta-cognitive ability and math problem-solving power of students at different levels of education," Procedia-Social and Behavioral Sciences, vol. 32, pp. 372-379, 2012.

[82] O. Olubunmi, "Effectiveness of problem of solving approach on gender related differences in teaching secondary school chemistry students mathematical concepts of chemistry in Ondo state, Nigeria," European Journal of Education Studies, vol. 2, 2016.

[83] M. Batubara and N. Nurbianta, "Teacher's communication mastership: groundwork and implication to pedagogy skill for effective teaching," Dinasti International Journal of Education Management and Social Science, vol. 2, pp. 34-40, 2020.

[84] E. Sung, "The influence of visualization tendency on problem-solving ability and learning achievement of primary school students in South Korea," Thinking Skills and Creativity, vol. 26, pp. 168-175, 2017.

[85] R. Fitri and R. Yogica, "Effectiveness of concept-based learning model, drawing and drill methods to improve student's ability to understand concepts and high-level thinking in animal development course," Journal of Physics: Conference Series, vol. 1116, no. 5, Article ID 052040, 2018.

[86] A. Sheriff, O. Ifedayo, and T. Yetunde, "Collaborative learning method: effects of ability levels and school-type on the junior secondary students' business studies achievement in Edo state," International Journal of Educational Research, vol. 6, pp. 198-207, 2019.

[87] E. H. Tsamago, "Exploring learners' conceptual development using computer simulation in a grade 10 science class," Doctoral dissertation, University of Limpopo, Mankweng, South Africa, 2017.

[88] P. Seeling and J. Eickholt, "Levels of active learning in programming skill acquisition: from lecture to active learning rooms," in Proceedings of the 2017 IEEE Frontiers in Education Conference (FIE), pp. 1-5, IEEE, Indianapolis, IN, USA, October 2017.

[89] B. Nworgu, Educational Measurement and Evaluation Theory and Practice, Nsukka: University Trust Publishers, Nsukka, Nigeria, 2015

[90] M. Cleves, W. Gould, W. Gould, R. Gutierrez, and Y. Marchenko, An Introduction to Survival Analysis Using Stata, Stata Press, College Station, TX, USA, 2008.

[91] M. Fuad, D. Deb, and J. Etim, “An evidence based learning and teaching strategy for computer science classrooms and its extension into a mobile classroom response system," in Proceedings of the 2014 IEEE 14th International Conference on Advanced Learning Technologies, pp. 149-153, IEEE, Athens, Greece, July 2014.

[92] G. Yansong, Q. Jin, and Y. Lili, "Research on scientific research performance evaluation based on the innovation ability by computer science," in Proceedings of the 2020 International Conference on Computer Science and Management Technology (ICCSMT), pp. 183-186, IEEE, Shanghai, China, November 2020.

[93] L. Wijnia, S. Loyens, and R. Rikers, "The problem-based learning process: an overview of different models," The Wiley Handbook of Problem-Based Learning, pp. 273-295, Wiley, Hoboken, NJ, USA, 2019.

[94] N. Indahwati, R. Tuasikal, and M. Al Ardha, "Developing project based learning ( $\mathrm{PBL}$ ) as a teaching strategy in physical education for preservice physical education teacher," Advances in Social Science, Education and Humanities Research, vol. 335, pp. 490-497, 2019.

[95] D. King, "New perspectives on context-based chemistry education: using a dialectical sociocultural approach to view teaching and learning," Studies in Science Education, vol. 48, pp. 51-87, 2012.

[96] J. Anyafulude, "Effects of problem-based and discoverybased instructional strategies on students' academic achievement in chemistry," Journal of Educational and Social Research, vol. 3, p. 105, 2013.

[97] J. Egbo, "Effect of concept mapping method of instruction on students' achievement and retention in chemistry," Journal of Technology and Education in Nigeria, vol. 5, pp. 7-11, 2004.

[98] A. Folashade and A. O. Akinbobola, "Constructivist problem-based learning technique and the academic achievement of physics students with low ability level in Nigerian secondary schools," European Journal of Physics, vol. 1, pp. $45-51,2009$. 
[99] B. Bloom, Taxonomy of Educational Objectives, Book 1 Cognitive Domain, Longmans, Harlow, UK, 1990.

[100] G. Mohammadyari, "Comparative study of relationship between general perceived self-efficacy and test anxiety with academic achievement of male and female students," Procedia-Social and Behavioral Sciences, vol. 69, pp. 2119-2123, 2012.

[101] N. Dasgupta, M. Scircle, and M. Hunsinger, "Female peers in small work groups enhance women's motivation, verbal participation, and career aspirations in engineering," Proceedings of the National Academy of Sciences, vol. 112, no. 16, pp. 4988-4993, 2015.

[102] F. Taghva, N. Rezaei, J. Ghaderi, and R. Taghva, "Studying the relationship between critical thinking skills and students" educational achievement (Eghlid Universities as case study)," International Letters of Social and Humanistic Sciences, vol. 25, pp. 18-25, 2014.

[103] G. Stump, J. Hilpert, J. Husman, W. Chung, and W. Kim, "Collaborative learning in engineering students: gender and achievement," Journal of Engineering Education, vol. 100, pp. 475-497, 2011.

[104] L. Gano, "Fitting technology to the mathematics pedagogy: its effect on students' academic achievement," in Proceedings of the E-Learn: World Conference on E-Learning in Corporate, Government, Healthcare, and Higher Education, pp. 987-993, Association for the Advancement of Computing in Education (AACE), Orlando, FL, USA, January 2010.

[105] K. Seashore, A. Anderson, and E. Riedel, "Implementing arts for academic achievement: the impact of mental models, professional community and interdisciplinary teaming," Report, Center for Applied Research and Educational Improvement, Falcon Heights, MN, USA, 2003.

[106] B. Dubbels, "Chapter four: pedagogy \& play: creating a playful curriculum for academic achievement and engaged learning," Learning, Education, and Games, ETC Press, Cambridge, MA, USA, 2016.

[107] Y. Ikeda, K. Kijima, K. Kawabata, T. Fuchimoto, and A. Ito, "Relationship between side medicine-ball throw performance and physical ability for male and female athletes," European Journal of Applied Physiology, vol. 99, pp. 47-55, 2007.

[108] J. Daybell, "Interpreting letters and reading script: evidence for female education and literacy in Tudor England," History of Education, vol. 34, pp. 695-715, 2005.

[109] S. Heyneman and B. Lee, "The impact of international studies of academic achievement on policy and research," Handbook of International Large-Scale Assessment: Background, Technical Issues and Methods of Data Analysis, pp. 37-72, Chapman and Hall/CRC, Boca Raton, FL, USA, 2014.

[110] H. Sadideen and R. Kneebone, "Practical skills teaching in contemporary surgical education: how can educational theory be applied to promote effective learning?" The American Journal of Surgery, vol. 204, pp. 396-401, 2012.

[111] K. Siddharth, "Statistical significance and sample size," 2019, https://explorable.com/statisticalsignificance-sample-size.

[112] J. Brown, "Sample size and power," Shiken: JALT Testing \& Evaluation SIG Newsletter, vol. 11, pp. 31-35, 2007.

[113] F. Lord and M. Novick, Statistical Theories of Mental Test Scores, Addison-Wesley, Boston, MA, USA, 1968.

[114] R. E. Traub, Reliability for the Social Sciences: Theory and Applications, SAGE Publications, Thousand Oaks, CA, USA, 1994. 